Instructions for authors, subscriptions and further details:

http://ijep.hipatiapress.com

\title{
Peers Influence Mathematics Strategy Use in Early Elementary School
}

Martha Carr, Nicole Barned, and Beryl Otumfuor ${ }^{1}$

1) University of Georgia

Date of publication: February 24th 2016

Edition period: February 2016 - June 2016

To cite this article: Carr, M., Barned, N., \& Otumfuor, B. (2016). Peers Influence Mathematics Strategy Use in Early Elementary School. International Journal of Educational Psychology, 5(1), 27-55. doi: 10.17583/ijep.2016.1861

To link this article: http://dx.doi.org/10.17583/ijep.2016.1861

\section{PLEASE SCROLL DOWN FOR ARTICLE}

The terms and conditions of use are related to the Open Journal System and to Creative Commons Attribution License (CC-BY). 


\title{
Peers Influence Mathematics \\ Strategy Use in Early
}

\section{Elementary School}

\author{
Martha Carr, Nicole Barned, Beryl Otumfuor \\ University of Georgia
}

\section{Abstract}

This study examined the impact of performance goals on arithmetic strategy use, and how same-sex peer groups contributed to the selection of strategies used by first-graders. It was hypothesized that gender differences in strategy use are a function of performance goals and the influence of same-sex peers. Using a sample of 75 first grade students, data were collected at three time-points throughout the school year. Hierarchical linear regression and repeated measures ANCOVAs indicated that performance goals predicted an increased use of retrieval and cognitive strategies, but only in boys. Accuracy in performance and an increased use of retrieval and cognitive strategies were found in all-boy groups, but not in all-girl groups. The study identifies performance goals and peers as playing a persuasive role in the use of retrieval and cognitive strategies for boys. Neither variable explained girls' preference for manipulative-based strategies.

Keywords: mathematics, strategies, peers, achievement-goals 


\section{Los Iguales Influyen en el Uso de Estrategias Matemáticas al Inicio de la Escuela Primaria}

Martha Carr, Nicole Barned, Beryl Otumfuor

University of Georgia

\section{Resumen}

El estudio examinó el impacto de los objetivos de rendimiento sobre el uso de estrategias aritméticas, y cómo grupos de iguales del mismo género contribuyeron a la selección de estrategias utilizadas por estudiantes de primer curso. Se hipotetizó que las diferencias de género en el uso de estrategias son una función lo de los objetivos de rendimiento y la influencia de iguales del mismo sexo. Utilizando una muestra de 75 estudiantes de primer grado, los datos se recogieron en tres momentos a lo largo del curso escolar. Regresión lineal jerárquica y medidas repetidas de ANCOVAs indicaron que los objetivos de rendimiento predijeron un mayor uso de estrategias de recuperación y cognitivas, pero solo en chicos. La precisión en el rendimiento y un mayor uso de estrategias de recuperación y cognitivas se encontraron en todos los grupos de chicos, pero no en todos los grupos de chicas. El estudio identifica los objetivos de rendimiento y los iguales jugando un papel persuasivo en el uso de estrategias de recuperación y cognitivas en los chicos. Ninguna de las variables explicó la preferencia de las chicas por estrategias basadas en la manipulación.

Palabras clave: matemáticas, estrategias, iguales, objetivos de logro

2016 Hipatia Press

ISSN: 2014-3591

DOI: $10.17583 /$ ijep.2016.1861 
tudents typically possess and use a range of strategies for solving mathematics problems (Siegler \& Jenkins, 1989). The development of these strategies follows an overlapping wave pattern so that at any time a student has access to multiple strategies and the use of these strategies changes as students discover and adopt increasingly complex strategies (Siegler, 1996; Svenson \& Sjöberg, 1983). While the acquisition and use of some strategies is linked to increasingly complex conceptual knowledge (e.g., Baroody \& Tiilikainen, 2003) and children's experiences with strategies influence strategy acquisition and selection, there is growing evidence that contextual factors influence strategy acquisition and selection.

Research has focused on the cognitive underpinnings of strategy acquisition and selection. Students acquire new strategies through a combination of associative and metacognitive processes with associative, automated processes operating when the task is familiar and metacognitive processes being activated when problems occur in strategy use or when children recognize more efficient strategies (Crowley, Shrager, \& Siegler, 1997). Siegler and Shipley (1995) proposed that students routinely select strategies as a function of their perceived accuracy and efficiency. Other researchers have focused on the role of conceptual knowledge in the development of new strategies (e.g., Baroody, Tiilikainen, \& Tai, 2006; Canobi, Reeve, \& Pattison, 1998; Steffe, Cobb, \& von Glaserfeld, 1988).

There is some variability in the selection of strategies that is not linked to students' conceptual knowledge or their experiences with strategies. Some students, labeled perfectionists, use retrieval less because they need to be certain they know an answer whereas "good" students use retrieval more often while being equally accurate (Siegler, 1988). Other research indicates gender differences in strategy use with girls preferring to use counting strategies that require manipulatives and boys preferring to use retrieval and cognitive strategies (Carr \& Jessup, 1997). Gender differences favoring more conservative strategies in girls have been found for division strategies, as well (Hickendorff, van Putten, Verhelst, \& Heiser, 2010).

It is unclear what produces this variability but one possibility may be the messages students receive from others regarding the value of certain strategies or the importance of speed versus accuracy in problem solving. This research examined the influence of same-sex peers on strategy 
selection, specifically, how they support the use of certain strategies. Additionally, we studied whether performance goals supported the use of cognitive and retrieval strategy use and whether performance goals had a negative relationship with strategies utilizing manipulatives.

\section{Contextual Effects on Strategy Use}

Social context and cultural norms influence strategy acquisition and use (Ellis, 1997), as evident in the types of strategies that emerge when children are calculating prices during street vending in contrast to the strategies they learn in a formal school setting (Nunes, Schliemann, \& Carraher, 1993). Within schools, mathematics instructional programs determine the types of strategies being taught. In the United States, teachers typically encourage students to utilize manipulatives, such as counting on fingers or other countable objects, before transitioning to mental counting and retrieval (Sarama \& Clements, 2009). In countries, such as the Netherlands, more emphasis is placed on cognitive manipulation of tens and ones (e.g., Beishuizen, Van Putten, \& Van Mulken, 1997). Children tend to adopt the strategies supported by teachers and parents.

Cobb and his colleagues (Cobb, Gresalfi, \& Hodge, 2009; Cobb \& Yackel, 1996) argue that learning mathematics is influenced by sociomathematical norms and that students shape these norms through their interactions with each other and the teacher. Normative identities and personal identities are argued to emerge within mathematics classrooms (Cobb, Gresalfi \& Hodge, 2009). Normative identities reflect mathematics norms and the requisites needed to meet those conventions. Personal identities reflect students' self-assessments in light of normative identities. Normative identities, and the values of the classroom, constantly change through student-teacher interactions in the classroom. It is through this process that students learn which strategies are valued and develop their identities as mathematics students. Within western cultures, students learn that fast and accurate strategies are valued (Ellis, 1997). As such, when students learn different strategies they learn more than procedures; they learn which strategies are considered signal high or low ability.

Although Cobb argues that normative identities are at the classroom level, gender differences in strategy use may indicate that children construct different norms with girls constructing personal and normative identities that 
support manipulative strategy use. Boys, in contrast, appear to construct identities that support a move to faster and more advanced strategies, including cognitive strategies and retrieval. There is no evidence that teachers instruct girls and boys to use different strategies. In fact, teachers appear to make efforts to decrease gender differences in strategy use by encouraging girls to use retrieval and boys to use manipulatives when necessary (Carr et al., 1999). It is unlikely that these gender differences are a function of direct instruction of strategies. Another possible source of these differences would be the achievement goals, particularly performance goals that evolve as students learn more about what it means to do mathematics. We hypothesized that boys, in particular, would become more focused on performance goals and that this would predict their adoption of retrieval and cognitive strategy use.

\section{Achievement Goals and Strategy Use}

Students with performance goals are concerned about looking smart whereas students with mastery goals are interested in acquiring knowledge and skill (Elliott \& Dweck, 1988). Performance goals were linked to seeking evidence of high ability and was found to produce shallow processing and poor learning (Dweck \& Elliott, 1983). Recently, it has become evident that performance-approach goals, which involve students seeking to show high ability, and mastery goals can occur together and have positive outcomes for self-efficacy and risk-taking (Pintrich, 2000).

Little is known about the achievement goals of elementary school age children or how these goals influence mathematics achievement. What little research has been done suggests that elementary school children tend to hold mastery orientation (e.g., Stipek \& Mac Iver, 1989), but there is some evidence that elementary school age children possess performance goals. Bong (2009) found that early elementary school age Korean children reported both mastery goals and performance-approach goals. Furthermore it was the performance-approach goals that were correlated with mathematics achievement (Bong, 2009). A study by Mägi, Lerkkanen, Poikkeus, Rasku-Puttonen, and Kidas (2010) found performance avoidance to be negatively related to mathematics performance in second and third grade students, but neither mastery goals or performance approach goals predicted performance. In another study, Newman and Schwager (1995) 


\section{Carr et al. - Peers Influence Strategy Use}

examined how orienting third and sixth grade students towards mastery or performance goals affected their help-seeking behavior. They found that students in the sixth grade, but not third grade, who were given a performance goal showed less interest than students given a mastery goal in getting help to solve a problem. These studies suggest that performance goals can emerge in early elementary school and appear to have an impact on elementary school students' mathematics performance when they do emerge. How and when they emerge may be a function of context. In the case of the Korean children, Bong (2009) reported that the school system places emphasis on proving ability so performance-approach goals would be expected.

Performance goals are socially constructed; students learn what is evidence of high or low ability from other students and their teachers (Ames, 1992; Carr et al., 1999; Meece, Anderman, \& Anderman, 2006). The group work common in today's classrooms has been found to focus students' attention on ability as the cause of outcomes (Ames, 1984), particularly when competition is involved (e.g., Butler \& Kedar, 1990). Achievement goals as they develop at the classroom level likely affect the normative identities of mathematics classrooms whereas goals that develop on the individual level likely affect the personal identities of students as mathematicians. In this study we examined goals on the individual level and how these goals affected and were affected by emerging gender differences in strategy use. We examined whether goals predicted change in strategy use or whether changes in strategy use occurred prior to change in goals. We also examined how goals influenced how children reacted while solving problems in same-sex groups.

\section{Gender and Strategy Use}

Gender differences in mathematics strategies emerge in the first and second grades with boys using retrieval and cognitive strategies and girls using manipulatives (Carr \& Jessup, 1997; Fennema, Carpenter, Jacobs, Franke, \& Levi, 1998). These gender differences are not strictly a matter of preference (Davis \& Carr, 2001). Gender differences have also been found in the strategies used to solve fraction problems with sixth grade boys being more likely to use cognitive strategies and girls being more likely to use written strategies (Hickendorff et al., 2010). Although Carr and Jessup (1997) found 
no gender differences in accuracy, Hickendorff and her colleagues found that boys' preference for cognitive strategies was not necessarily adaptive because it often produced incorrect solutions.

Several social and motivational factors may push children to use different strategies. Boys tend to be competitive in their play and be motivated by competition in general (Goldstein, 1994; Weinberger \& Stein, 2007) and in mathematics (Boekaerts, Seegers, \& Vermeer, 1995; Knight \& Chao, 1989; Seegers \& Boekaerts, 1996). Boys are more likely than girls to take risks (Ridley \& Novak, 1983). Middle school age boys are more concerned than girls about looking smart (Anderman \& Midgley, 1997; Roeser, Midgley, \& Urdan, 1996; Seegers \& Boekaerts, 1996) and this seems to drive their preference for cognitive strategies and retrieval (Carr et al., 1999). Although not necessarily more accurate, these strategies have the advantage of being fast and boys may be willing to use these strategies, even though there is a higher chance of failure. This may be particularly true when working in groups where competition and performance goals are highlighted.

It is less clear why girls tend to use manipulatives. Girls tend to play cooperatively and prefer cooperative interactions (Knight \& Chao, 1989; Maccoby, 1990), and they are more compliant in the classroom (KenneyBenson, Pomerantz, Ryan, \& Patrick, 2006). This may translate into a tendency to use strategies explicitly taught in the classroom. In recent years, the focus in early elementary school mathematics classrooms has been on manipulatives. Alternately, girls may use manipulatives because they view themselves as having lower ability. There is some evidence that elementary school age girls view failure in mathematics as being due to low ability and success as being due to effort, whereas boys view success as an indicator of high ability (Seegers \& Boekaerts, 1996). Such attributional patterns may discourage the use of retrieval and cognitive strategies in favor of manipulatives. Given that mathematics ability tends to be viewed as a stable, innate trait, it makes sense that girls would avoid strategies that may highlight low competence.

\section{The Present Study}

This study explored whether preference for performance goals over mastery goals supports the shift to retrieval and cognitive strategy use. If the focus 


\section{Carr et al. - Peers Influence Strategy Use}

on ability, speed, and looking smart drives the use of these strategies then a shift towards performance goals from mastery goals or initially high performance goals should predict the later use of retrieval and cognitive strategies. Given that boys tend to make this shift faster, this should be especially true for them. However, an alternative hypothesis would be that the emergence of retrieval and cognitive strategies predicts an increase in performance over mastery goals with a more performance goal orientation emerging as these strategies are labeled as indicating high ability. Given that the focus was on gender identities as mathematicians, this study focused on same-sex peers. We used same-sex groupings because gender differences are more likely to be expressed in these settings (Maccoby, 1990). If boys and girls are motivated by gender-specific norms then an increase in the use of retrieval and cognitive strategy use in boys and manipulatives in girls would be expected as students work in same-sex groups. We also examined whether there were gender differences in achievement goals.

This study used a longitudinal design in which children were interviewed individually twice, once at the beginning of the school year and once at the end of the school year. This allowed us to measure change in strategy use and attitudes across the full year. The children were interviewed in groups of three in January so that the impact of beginning of year strategy use and beliefs on group interactions could be assessed as well as the impact of group dynamics on strategy use at the end of the school year. It was decided to assess group interactions in January because this timepoint was equidistant from the two individual assessments allowing several months break between individual sessions and the group sessions.

\section{Method}

\section{Participants}

Seventy-five first grade students (40 males and 35 females) attending an elementary school in Northeast Georgia were recruited to participate in the study. The students were seen three times during the school year in October, January, and April. All 75 students participated in the October session, but strategy data from two participants (one male and one female) were lost due to a technical malfunction in the camera. Sixty-seven students (35 males) 
participated in the group session in January and 68 students (37 males and 31 females) completed the third session in April. Complete data from all three sessions exist for 66 students (36 males). The students who did not complete all three waves had moved from the school and were missing at random. Their strategy scores did not differ significantly from those of their peers. The average age of the students at the beginning of the school year was $(M=6.4, S D=.88)$. Eighty-eight percent of the sample was White, 12 percent was African-American, five percent was Asian, and five percent was Latino.

\section{Procedures and Materials}

Individual interviews in October and April. In October and April all participating students were interviewed individually in a quiet conference room. The sessions were videotaped to allow for later coding of strategy use and inter-rater reliability. The students were assessed on their strategy use for 14 computation problems (see Appendix A) of which five were missing addend problems, half addition and half subtraction problems. The students also solved six word problems (3 addition, 3 subtraction). Plastic counters were made available for use. After each problem was solved the student was asked how he or she solved that problem. The students used an array of counting strategies. Students' explanations about their strategy use and observations of strategy use were used to categorize strategy use. Because the focus of this study was on the impact of perceived social desirability and emerging performance goals on strategy use, strategies were categorized into manipulative-based strategies, which were hypothesized to indicate low ability and high effort, and retrieval/cognitive strategies, which were hypothesized to indicate high ability and lower effort. The cognitive and retrieval strategies category included both mental calculation and retrieval because retrieval was too rarely used (on average only five percent of the time) to warrant a separate category. Four categories of strategy use were used in the analyses: percent correct and percent attempted for retrieval/cognitive strategy use and percent correct and percent attempted use of manipulatives. Interrater reliability for this measure was .89.

Following this, the children were assessed on their understanding of what it means to be smart through the use of two interview questions and four 


\section{Carr et al. - Peers Influence Strategy Use}

Likert scales. For the two interview questions the children were asked, "If a kid is smart at math how does he (she) do math? Are there ways to do math that you think are not so smart?" In the fall more than $50 \%$ of the children stated that the use of manipulatives was evidence that a student was smart whereas $37 \%$ indicated that cognitive strategies or retrieval indicated a student was smart. As such, students did not orient toward performance goal responses for these questions. Students' responses for questions the questions were scored as indicating performance goals if they referred to the use of retrieval or cognitive strategies, indicated that being smart meant not seeking help, that a smart student would find problem solving easy, that notso-smart students used manipulatives, needed help, or had trouble with difficult items. When children's responses indicated that smart students (question one) used manipulatives, sought help during problem solving, used effort, or when children responded that not-so-smart students (question two) used retrieval or cognitive strategies, the responses were scored as a mastery goal orientation. Students gave one response per question for a range between zero and two points for the performance and mastery goal categories.

Next, the students were asked four questions designed to further assess performance and mastery goal orientations. They were asked whether it was good to try to retrieve the answer from memory, whether it was good to be the first to answer questions, and whether guessing was acceptable. For this task, students were instructed to put down five stars if the statement was very true, if they thought the statement was not very true, they were to put down fewer stars. They were then given two trial examples, "I like ice cream" and "I like carrots". Once the child understood the task four statements were presented. For each of the questions scores ranged from zero to five stars.

Students' scores for the first statement was added to their mastery goal score from the two open questions for a total possible combined score of 3 . Students' scores for the last three statements were added to the performance goal score for a total possible score of 5. Finally, the mastery goal score was subtracted from performance goal score to create a single variable that reflected the relationship between performance orientation and mastery orientation so that a high score reflected a tendency to give performance goal rationales over mastery goal responses. Because high scores reflect a 
performance goal orientation over a mastery goal orientation this variable is referred to as performance goals in the analyses and discussion.

Group interviews in January. In January, students were split into same-sex groups of three. There were 24 groups total with 13 girl groups (one group with 2 members) and 11 boy groups (one group with 2 members). When possible, the groups were comprised of students from the same class in order to better estimate the role of social relationships within classrooms on strategy use.

The students were told that they would take turns solving addition and subtraction problems and that it was acceptable to talk about what they or the other students were doing. Seven sets of addition and subtraction problems used in the individual session were used with the exception of the missing-addend problems. Because there were only two missing addend problems included in the individual session, three new addition items were created for the group work so that all children did an addition missing addend problem (see Appendix A). Strategy use was assessed through observation and the child's report of strategy use. Percent correct and attempted for retrieval and cognitive strategies and percent correct and attempted for manipulative-based strategies were computed with a possible range within each category between zero and seven.

\section{Results}

\section{Gender Differences in Strategy Use}

We first examined whether there were gender differences in strategy use and performance goals. Means and standard deviations for strategy use as measured in October, January and April and for performance goals as measured in October and April are presented in Table 1. 
38 Carr et al. - Peers Influence Strategy Use

Table 1

Means and standard deviations for performance goals and strategy use

Performance goals

Fall Spring Winter

$\begin{array}{clll}\text { Males } & 3.95(2.75) & 4.16(3.21) & - \\ \text { Females } & 3.93(2.70) & 2.87(2.60) & -\end{array}$

$\%$ Attempted Ret/Cog

$\begin{array}{cccc}\text { Males } & .22(.24) & .36(.32) & .53(.29) \\ \text { Females } & .07(.15) & .16(.18) & .23(.25)\end{array}$

$\%$ Correct Ret/Cog

Males

Females

$\%$ Attempted Manipulatives

Males

$\begin{array}{lll}.13(.16) & .25(.25) & .23(.23) \\ .05(.12) & .13(.15) & .12(.17)\end{array}$

Females

$.47(.29) \quad .43(.31) \quad .44(.29)$

$.54(.32) \quad .65(.23) \quad .73(.25)$

$\%$ Correct Manipulatives

Males

Females

Repeated measures analyses of variance with percent correct use of retrieval/cognitive strategies comparing change from October to April indicated a gender effect, $F(1,63)=5.92, p=.02, \eta_{p}{ }^{2}=.09$, and a time effect, $F(1,63)=25.26, p<.001, \eta_{p}{ }^{2}=.29$. A similar pattern was found for percent attempted use of retrieval/cognitive strategies with a time effect, $F(1,63)=19.47, p<.001, \eta_{p}{ }^{2}=.24$, and a gender effect, $F(1,63)=10.89, p$ $=.002, \eta_{p}{ }^{2}=.15$. All students increased the correct and attempted use of these strategies over the first grade, but boys consistently attempted and correctly used these strategies more often. A repeated measures analysis of percent correct use of manipulative-based strategies comparing change from October to April with gender as the independent variable indicated a significant change over time, $F(1,63)=5.11, p=.03, \eta_{p}{ }^{2}=.08$ and a significant gender effect, $F(1,63)=7.28, p=.009, \eta_{p}{ }^{2}=.10$. A repeated measures analysis of attempted use of manipulative-based strategies indicated a significant gender, $F(1,63)=5.08, p=.03, \eta_{p}{ }^{2}=.08$, and gender by time interaction, $F(1,63)=4.09, p=.05, \eta_{p}^{2}=.06$ (see Figure 1$)$. 


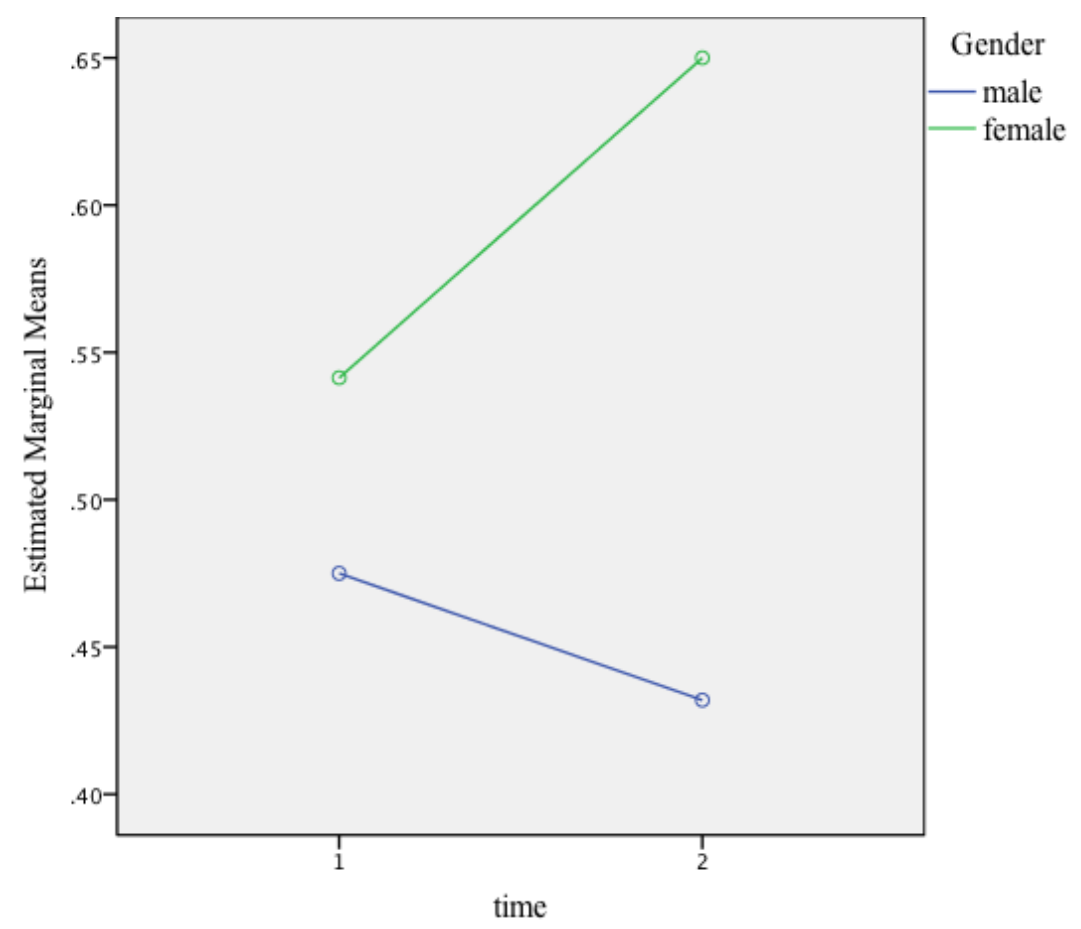

Figure 1. Percent attempted use of manipulatives

Whereas, girls tended to attempt and correctly use manipulative-based strategies more than boys, boys seem to decrease attempted use of these strategies across the first grade while girls increased their attempted use of these strategies.

Although boys tended to increase reported performance goals over the school year and girls tended to report a decrease in performance goals, the repeated measure analyses of performance goals with gender as the independent variable indicated no significant differences for time or gender.

\section{Changes in Strategy use as a Function of Goals and Gender}

We hypothesized that boys' preference for retrieval and cognitive strategies was, in part, driven by performance goals. We hypothesized that boys would be more likely to hold performance goals and these goals would drive the 
acquisition of retrieval and cognitive strategies. Although boys were not found to hold performance goals more than girls, these goals still might differentially affect their use of strategies. In contrast, for girls, a low score on the performance goal variable indicating more mastery goals was expected to predict their increased use of manipulatives over the year.

To examine this, a change score was created by subtracting strategy use, as measured in October, from strategy use as measured in April. The impact of gender, October performance goals and a gender by performance goals interaction term on the change scores was assessed in a hierarchical linear regression. Gender and October performance goals were predictors in the first model and the gender x performance goals interaction term was tested in the second model. For easier interpretation the interaction scores, performance goal, and strategy use scores were changed to z-scores.

Retrieval and cognitive strategies. The first model examining predictors of change in student's attempted use of retrieval/cognitive strategies with October performance goals and gender as predictors was significant, $F(2,63)=5.28, p=.008, R^{2}=14$. Performance goals measured in October, but not gender, significantly predicted change in attempted use of retrieval and cognitive strategies, $\beta=.37, p<.003$. Model two included the gender by performance goal interaction term that was significant, $F(3,62)=5.35$, $p=.002, R^{2}$ change=.06, $p=.03$. In model two, both October performance goals, $\beta=.61, p<.001$, and the gender by performance goals interaction term, $\beta=-.52, p=.03$, were significant. In interpreting the interaction, for boys for every one unit change in fall performance goals there is a .61 change in percent attempted retrieval/cognitive strategies whereas for girls that change is only .08. For boys, in comparison to girls, percent attempted retrieval and cognitive strategy use appeared to change as a function of performance goals.

For correct use of retrieval and cognitive strategies, model one was significant, $F(2,63)=4.51, p=.02, R^{2}=.13$. In model one, fall performance goals significantly predicted the change in the correct use of retrieval/cognitive strategies, $\beta=.35, p=.007$. Model two indicated that the addition of the interaction term produced a significant increase in explained variance, $F(3,61)=4.58, p=.006, R^{2}$ change $=.06, p=.04$, with both fall performance goals $(\beta=.58, p=.001$, and the interaction, $\beta=-.51, p=.04$, being 
significant predictors of change in the correct use of retrieval and cognitive strategies. In interpreting the interaction, for each unit change in fall performance goals there is a .58 change in correct retrieval and cognitive strategy use for boys. For females that change is .07. As with percent attempted retrieval and cognitive strategy use, there is more change in percent correct retrieval and cognitive strategy use for males than for females.

Manipulative-based strategies. In examining change in the attempted use of manipulatives, model one was significant, $F(2,63)=4.45, p=.02, R^{2}=.12$. In this model, both gender, $\beta=.50, p=.04$, and October performance goals, $\beta=-.25, p=.05$ predicted change in the attempted use of manipulatives. Performance goals were negatively related to this form of strategy use and girls were more likely to attempt the use of manipulatives. Model two, which included the gender $\mathrm{x}$ performance goals interaction term, did not indicate a significant change in explained variance as a result of the addition of the interaction term.

In examining changes in correct use of manipulatives from fall to spring, neither model one or model two were significant, $F(2,63)=2.76, p=.07$ and $F(3,62)=1.85, p=.15$, respectively. Correct use of these strategies was not predicted by gender or performance goals.

\section{Influence of Strategy Use and Gender on Performance Goals}

We examined the possibility that the development of performance goals in early elementary school might be a function of the changes to strategy use. In theory, children who were earlier adopters of retrieval and cognitive strategies would be labeled as smarter. We explored this possibility by examining whether change in performance goals from October to April was predicted by October strategy use, gender, or a gender by strategy use interaction. None of the regression equations were significant. These results provide little evidence that gender differences in strategy use produces changes in performance goals.

\section{The Impact of Group on Strategy Selection}

A second goal of the study was to examine how same-sex grouping influence the strategies that girls and boys use. If strategy use is influenced 


\section{Carr et al. - Peers Influence Strategy Use}

by group norms and there are gender specific norms for strategy use then we should see more pronounced use of retrieval and cognitive strategy use in boy groups and the use of more manipulative-based strategies in girl groups in comparison to the individual sessions. Furthermore, gender differences in strategy use should become more pronounced as students solve problems ingroup.

Comparing group to individual strategy use. If working in groups accentuates boys' tendencies to use retrieval and cognitive strategies and girls' tendencies to use manipulatives we should see more pronounced preferred strategy use in January when students are working in-group in comparison to individual strategy use as measured before and after the group work. We ran repeated measures ANCOVAs with gender as the independent variable and October performance goals as the covariate with percent attempted use of retrieval/cognitive strategies and percent attempted of manipulatives as measured in October, January, and April as the dependent variables.

The repeated measures ANCOVA of percent attempted use of retrieval/cognitive strategies indicated a significant quadratic effect for time, $F(1,63)=8.12, p=.006, \eta_{p}{ }^{2}=.11$, and a significant linear time by performance goals interaction, $F(1,63)=9.28, p=.003, \eta_{p}{ }^{2}=.13$. There was also a significant gender effect with boys being more likely to attempt the use of retrieval/cognitive strategies, $F(1,63)=18.88, p<.001, \eta_{p}{ }^{2}=.23$. In examining the influence of performance goals on each of the three time points, performance goals significantly correlated with percent attempted use of retrieval/cognitive strategy use in January, $r=.30, \mathrm{p}=.02$, and in April, $r=.42$, $\mathrm{p}=.001$, but not in October.

The repeated measures ANCOVA of percent attempted use of manipulatives indicated a linear time effect with this strategy use increasing over time, $F(1,63)=4.99, p=.03, \eta_{p}{ }^{2}=.07$, a significant gender effect with girls using the strategy more than boys, $F(1,63)=9.99, p=.002, \eta_{p}{ }^{2}=.14$, a significant linear time by gender interaction, $F(1,63)=4.48, p=.04, \eta_{p}{ }^{2}=.07$, and a significant linear time by performance goals interaction, $F(1,63)=4.19, p=.05, \eta_{p}{ }^{2}=.06$. The gender by time interaction, displayed in Figure 2, indicates that girls' attempted use of manipulatives increased over the school year whereas boys' attempted use of manipulatives remained relatively stable. Although there was a slight uptick in the attempted use of 
manipulatives in the group session it was not sufficient to produce a quadratic trend. Correlations of performance goals with attempted strategy use at each time point indicated a negative significant correlation in January, $\mathrm{r}=-.25, \mathrm{p}=.05$ and April, $\mathrm{r}=-.25, \mathrm{p}=.05$, but not in October.

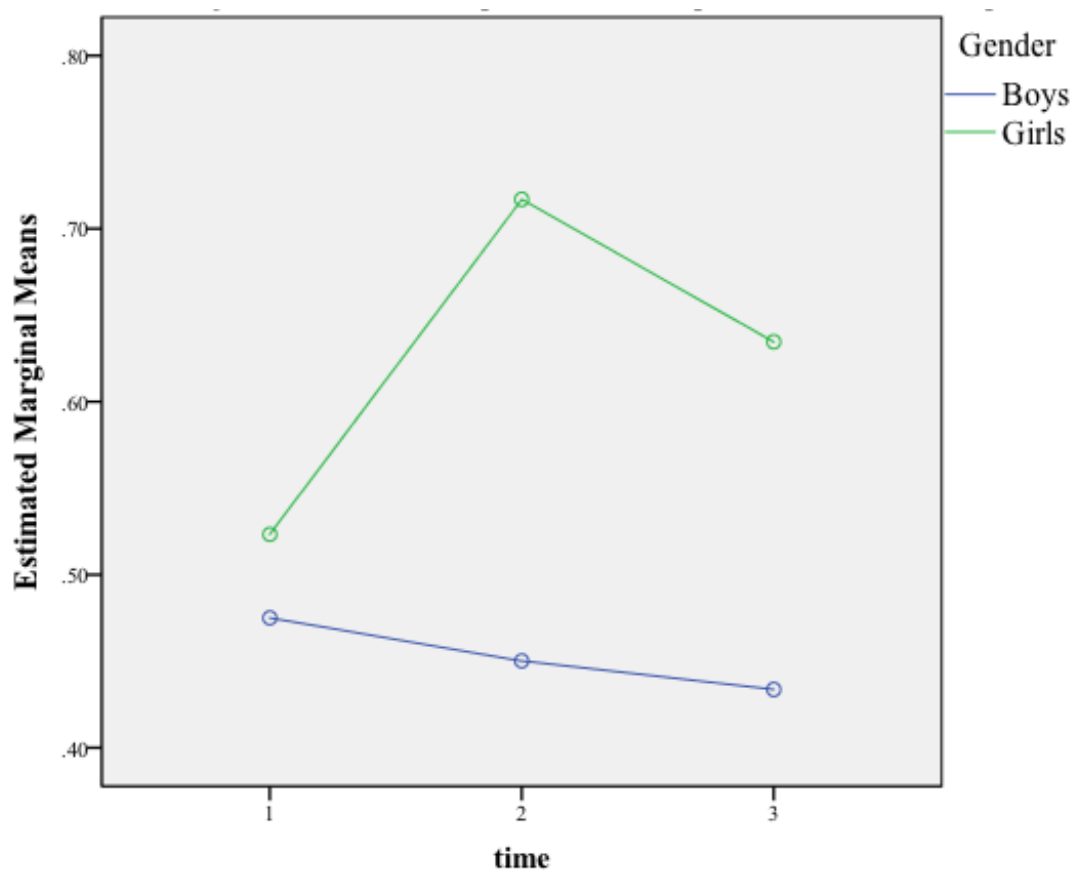

Figure 2. Percent attempted use of manipulatives across 3 timepoints

Change within sessions. To examine the impact of peers on strategy use we observed strategy use change within a single session with the children taking turns solving seven problems. We used repeated measure analyses of variance with attempted and correct strategy use as the dependent variable and group gender as the independent variable. Although the main focus was on attempted use of different strategies we also wanted to examine how group interaction may affect the accuracy of the solutions.

The first analysis included percent attempted use of retrieval/cognitive strategies as the dependent variable and group gender as the independent 


\section{Carr et al. - Peers Influence Strategy Use}

variable. The results indicated that male groups consistently used these strategies more than female groups, $F(1,21)=8.67, p=.008, \eta_{p}{ }^{2}=.29$. When the correct use of retrieval and cognitive strategies was examined the group gender differences, $F(1,21)=11.11, p=.003, \eta_{p}{ }^{2}=.35$, were accompanied by an interaction effect indicating that boys' percent correct use of these strategies increased over the seven sets $F(1,21)=6.42, p=.02$, $\eta_{p}{ }^{2}=.23$ (see Figure 3). These data indicate that repeated efforts to use retrieval and cognitive strategies resulted in improved accuracy over time for boys, but not girls.

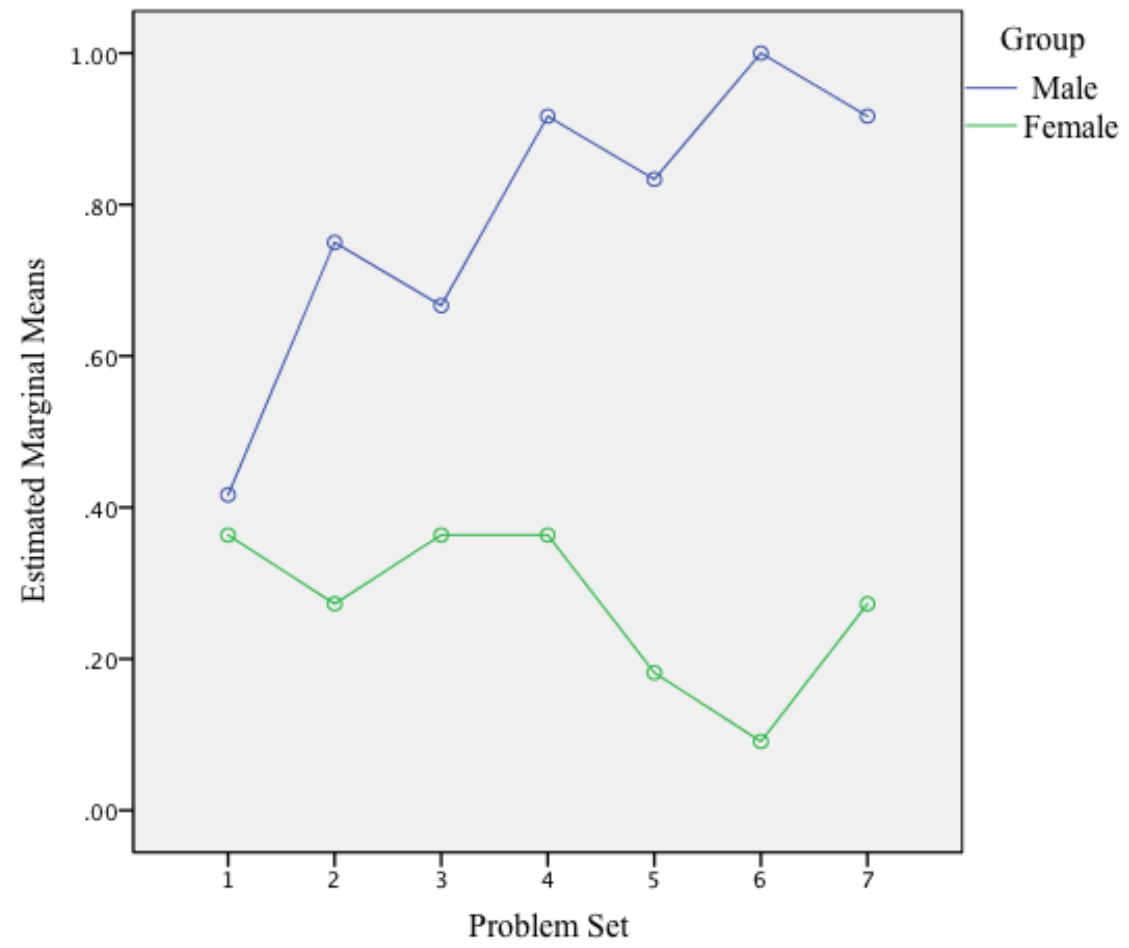

Figure 3. Average correct use of retrieval and cognitive strategies in group

When examining the use of manipulatives, girl groups were more likely to attempt to use these strategies, $F(2,21)=11.65, p=.003, \eta_{p}{ }^{2}=.36$. In examining the percent correct use of these strategies, girls showed a 
consistently higher pattern of the correct use of manipulatives across the sets, $F(1,21)=7.41, p=.01, \eta_{p}{ }^{2}=.26$. These data indicate more stability in the use of manipulatives and little evidence of increased use over time.

October performance goals and group strategy use. We examined the impact of performance goals as measured in October on group strategy use in January as a function of gender. Correlational analyses (see Table 2) indicated that for boys, but not girls, performance goals in October were correlated with attempted use of retrieval and cognitive strategies in the group session $(r=.49)$. Likewise, October performance goals were negatively correlated with attempted $(r=-.42)$ and correct manipulativebased strategy use in groups ( $r=-.42$ ) for boys, but not girls. For girls, performance goals as measured at in October did not predict strategy use ingroup. These data suggest that the increased use of retrieval for boys is linked to earlier emerging performance goals, and these goals seem to take the form of avoiding the use of manipulatives and attempting to use retrieval and cognitive strategy use.

Table 2

Correlations of performance goals with January group strategy use

$\begin{array}{cc}\text { Performance } & \text { Performance } \\ \text { Goals } & \text { Goals } \\ \text { Fall } & \text { Spring }\end{array}$

Percent Attempted Ret/Cog

Percent Correct Ret/Cog

$\begin{array}{rll}\text { Males } & .49^{* *} & .27 \\ \text { Females } & .10 & .18\end{array}$

Percent Correct Manipulatives

$\begin{array}{rll}\text { Males } & .30 & .31 \\ \text { Females } & .20 & .19\end{array}$

Percent Attempted Manipulatives

$\begin{array}{rll}\text { Males } & -.42 * * & -.25 \\ \text { Females } & -.05 & -.17\end{array}$

$\begin{array}{rcc}\text { Males } & -.43 * * & -.19 \\ \text { Females } & .20 & .15\end{array}$




\section{Carr et al. - Peers Influence Strategy Use}

Finally, we examined whether strategy use predicted students' performance goals. Correlation analyses were performed between in-group strategy use as measured in January and students' performance goals as measured in the April. We found no correlation between group strategy use and April performance goals. These data provide further evidence that it is performance goals that influence the emergence of strategies and not vise versa.

\section{Discussion}

This study replicated prior findings of gender differences in strategy use in early elementary school (Carr \& Davis, 2001; Carr \& Jessup, 1997; Carr, Steiner, Kyser \& Biddlecomb, 2008). We found that boys consistently used retrieval and cognitive strategies in comparison to girls who attempted and correctly used manipulative-based strategies more often than boys. The goal of this study was to determine whether performance goals affected the emergence of these gender differences. It also examined the impact of peers and performance goals on strategy use by examining changes in strategy use within a single session.

We extended prior research by showing that boys move to more advanced strategies is influenced by performance goals. Performance goals as measured in October predicted change in the use of retrieval and cognitive strategies use between October and April and predicted the use of these strategies in-group in January for boys. Furthermore, performance goals were negatively related to the use of manipulative-based strategies. This finding is consistent with prior research indicating that performance goals have been linked to mathematics achievement (Eccles \& Midgley, 1989). It is also consistent with prior research in which first grade students' comments about wanting to look smart were correlated with the use of retrieval and cognitive strategy use for both boys and girls (Carr \& Jessup, 1997). Our results indicate that performance goals appear to drive change in retrieval and cognitive strategy use in boys, but not girls.

A test of the alternative pattern in which strategy use would predict changes in performance goal orientations was not supported. Strategy use as measured in October did not predict change in achievement goals nor was strategy use as measured in January correlated with April performance goals. It was thought that strategy use might drive changes in performance goals as 
peers and teachers interpret the use of retrieval and cognitive strategies as signs of high ability, but the data does not support this.

A second way to examine the impact of gender on the emergence of strategies was to examine problem solving within same-sex groups. Prior research (Carr \& Jessup, 1995) indicated that mixed-gender small groups resulted in an increase in the use of retrieval. In this study we assumed that same-sex groups would increase the likelihood of girls' use of manipulatives and boys' use of retrieval and cognitive strategies. As predicted boys showed increased use of retrieval and cognitive strategies during the session. In the case of correct retrieval and cognitive strategy use, boys significantly increased the accuracy with which they used retrieval and cognitive strategies over the seven sets of problems. Observations of boys' behaviors suggested that boys were actively observing each other's strategy use and trying to meet or exceed the prior boy's strategy selection. No such interactions were observed in the all girl groups. These data suggest that, at least for boys, these goals encourage the use of more advanced strategies and the increased efforts to use these strategies results in better accuracy.

That was not the case for girls.

In addition, when we compared individual strategy use to group strategy use we found a significant jump for boys in the use of retrieval in comparison to individual strategy use. We found, a quadratic pattern in strategy use with a significant upturn in attempted and correct retrieval and cognitive strategy use for boys, but not girls, in the group session in comparison to the individual sessions in October and April. These data are in line with prior research indicating that classroom characteristics, such as group work increased social comparison and a focus on ability (Ames, 1984; Butler \& Kedar, 1990). In this case, for boys, group work provides opportunities for social comparison and that appears to drive the shift to retrieval and cognitive strategies. This is not necessarily a problem if boys are relatively accurate because this process may impel boys towards fluency in their arithmetic. However, if boys are not accurate such behavior could result in a pattern of poor problem solving as the children progress through school.

Although performance goals were negatively related to the attempted use of manipulatives this pattern was not specific to girls, so gender differences in these strategies did not appear to be supported by a more mastery goal 


\section{Carr et al. - Peers Influence Strategy Use}

orientation. Unfortunately, the results of this study did not provide much insight into girls' tendency to use manipulatives. If girls tended toward mastery over performance goals we would expect to see a negative correlation between the performance goal variable and the use of manipulatives for girls. That correlation was not evident. Nor was there evidence that problem solving in same-sex groups of girls would result in an increase in manipulative-based strategies during the session. We cannot conclude that girls feel peer pressure to use these strategies.

\section{Limitations and Future Research}

Cobb (2001) found that teachers create very different contexts and norms for mathematics in their classrooms. One limitation with this study was the somewhat artificial setting in which to observe strategy use. The method allowed us to control for potential confounding variables that might influence strategy use, such as the problems being solved. Although the children who participated were drawn from a variety of first grade classrooms increasing the generalizability of the data, future research needs to examine how gender differences in strategy use are moderated by classroom level effects. Qualitative observations of children's interactions in regular classrooms would support the validity of our findings.

Although the children in this study were enrolled in schools that had about $50 \%$ free or reduced lunch the sample was not very racially diverse, nor did we compare the strategy use of children of different ability levels or from different socio-economic classes. Low performing children commonly use manipulatives so we may not find gender differences showing boys' preference for retrieval and cognitive strategies among low performing children. Future research needs to examine whether these gender differences arise across socio-economic groups or whether there are developmental delays as a function of ability level or social class.

The failure to examine changes in strategy use in mixed groups is another limitation. Carr and Jessup (1997) found that boys were more likely to make remarks about competitiveness even in mixed gender groups. The inclusion of mixed gender groups would have allowed us to examine how groups of varying size and gender mixtures would affect the use of retrieval and cognitive strategies in-group. However, it was decided to forgo the use 
of mixed gender groups in order to have a large enough sample size of single-gender groups.

In regard to future research, the finding that boys' accuracy improved during the group sessions as they increased their use of retrieval and cognitive strategies suggests that both boys and girls might benefit from the move to use more advanced strategies when solving mathematics problems, particularly retrieval and cognitive strategies. Research in the area of memory (Roediger \& Butler, 2011) indicates that efforts to retrieve information from memory increases retention and accuracy more so than studying the material. Even attempting to use retrieval and cognitive strategies regardless as to the accuracy of the answer results in improved strategy use and better academic outcomes (Carr \& Alexeev, 2011). In our study, efforts to retrieve or cognitively compute an answer produces increasingly accurate responses. Although boys' use of retrieval and cognitive strategies may initially be socially driven, practice with these strategies may result in improved ability to recall and mentally calculate answers, resulting in better performance for boys in no-choice strategy conditions.

\section{References}

Ames, C. (1984). Achievement attributions and self-instructions under competitive and individualistic goals structures. Journal of Educational Psychology, 76, 478.

Ames, C. (1992). Classrooms: Goals, structures, and student motivation. Journal of Educational Psychology, 84(3), 261-271. doi: 10.1037/0022-0663.84.3.261

Anderman, E. M., \& Midgley, C. (1997). Changes in achievement goal orientations, perceived academic competence, and grades across the transition to middle-level schools. Contemporary Educational Psychology, 22(3), 269-298. doi: 10.1006/ceps.1996.0926

Baroody, A., Tiilikainen, S., \& Tai, Y. (2006). The application and development of an addition goal sketch. Cognition and Instruction, 24(1), 123. doi: 10.1207/s1532690xci2401_3

Baroody, A. J., \& Tiilikainen, S. H. (2003). Two perspectives on addition development. In A. J. Baroody \& A. Dowker (Eds.), The development 
of arithmetic concepts and skills: Constructing adaptive expertise (pp. 75). Mahwah, NJ: Lawrence Erlbaum Associates Publishers.

Beishuizen, M., Van Putten, C. M., \& Van Mulken, F. (1997). Mental arithmetic and strategy use with indirect number problems up to one hundred. Learning \& Instruction, 7, 87.

Boekaerts, M., Seegers, G., \& Vermeer, H. (1995). Solving math problems: Where and why does the solution process go astray? Educational Studies in Mathematics, 28, 241.

Bong, M. (2009). Age-related differences in achievement goal differentiation. Journal of Educational Psychology, 101(4), 879-896. doi: $10.1037 / \mathrm{a} 0015945$

Butler, R., \& Kedar, A. (1990). Effects of Intergroup Competition and School Philosophy on Student Perceptions, Group Processes, and Performance. Contemporary Educational Psychology, 15, 301-318.

Canobi, K. H., Reeve, R. A., \& Pattison, P. E. (1998). The role of conceptual understanding in children's addition problem solving. Developmental Psychology, 34, 882.

Carr, M., \& Jessup, D. L. (1997). Gender differences in first-grade mathematics strategy use: Social and metacognitive influences. Journal for Educational Psychology, 89, 318-328.

Carr, M., Jessup, D. L., \& Fuller, D. (1999). Gender differences in first grade mathematics strategy use: Parent and teacher contributions. Journal for Research in Mathematics Education, 30, 1.

Carr, M., Steiner, H., Kyser, B. \& Biddlecomb, B. (2008). A comparison of predictors of early emerging gender differences in mathematics competency, Learning and Individual Differences, 18, 61-75.

Carr, M., \& Alexeev, N. (2011). Fluency, accuracy, and gender predict developmental trajectories of arithmetic strategies. Journal of Educational Psychology, 103, 617-631.

Cobb, P., Gresalfi, M., \& Hodge, L. L. (2009). An interpretive scheme for analyzing the identities that students develop in mathematics classrooms. Journal for Research in Mathematics Education, 40(1), 40-68.

Cobb, P., \& Yackel, E. (1996). Constructivist, emergent, and sociocultural perspectives in the context of developmental research. Educational Psychologist, 31(3-4), 175-190. doi: 10.1207/s15326985ep3103\&4_3 
Crowley, K., Shrager, J., \& Siegler, R. S. (1997). Strategy discovery as a competitive negotiation between metacognitive and associative mechanisms. Developmental Review, 17, 462.

Davis, H., \& Carr, M. (2001). Gender differences in mathematics strategy use: The influence of temperament. Learning and Individual Differences, 13(1), 83. doi: 10.1016/s1041-6080(02)00063-8

Dweck, C. S., \& Elliott, E. S. (1983). Achievement motivation. In E. M. Hetherington (Ed.), Socialization, personality and social development (Vol. 3, pp. 643). New York: Wiley.

Eccles, J., Midgley, C., Buchanan, C., Wigfield, A., Reuman, D., MacIver, D. (1993). Development During Adolescence: The Impact of Stage/Environment Fit on Young Adolescents' Experiences in Schools and Families. American Psychologist, 48(2), 90-101.

Elliott, E. S., \& Dweck, C. S. (1988). Goals: An approach to motivation and achievement. Journal of Personality and Social Psychology, 54(1), 5. doi: 10.1037/0022-3514.54.1.5

Ellis, S. (1997). Strategy choice in sociocultural context. Developmental Review, 17(4), 490.

Fennema, E., Carpenter, T. P., Jacobs, V. R., Franke, M. L., \& Levi, L. (1998). A longitudinal study of gender differences in young children's mathematical thinking. Educational Researcher, 27(5), 6.

Goldstein, J. H. (1994). Sex differences in toy play and use of video games. In J. H. Goldstein (Ed.), Toys, play, and child development (pp. 110). Cambridge: Cambridge University Press.

Hickendorff, M., van Putten, C. M., Verhelst, N. D., \& Heiser, W. J. (2010). Individual differences in strategy use on division problems: Mental versus written computation. Journal of Educational Psychology, 102(2), 438. doi: 10.1037/a0018177

Kenney-Benson, G. A., Pomerantz, E. M., Ryan, A. M., \& Patrick, H. (2006). Sex differences in math performance: The role of children's approach to schoolwork. Developmental Psychology, 42(1), 11.

Knight, G. P., \& Chao, C.-C. (1989). Gender differences in cooperative, competitive, and individualistic social values in children. Motivation and Emotion, 13, 125. 


\section{Carr et al. - Peers Influence Strategy Use}

Maccoby, E. E. (1990). Gender and relationships: A developmental account. American Psychologist, 45(4), 513-520. doi: 10.1037/0003066X.45.4.513

Mägi, K., Lerkkanen, M. K., Poikkeus, A. M., Rasku- Puttonen, H., \& Kikas, E. (2010). Relations Between Achievement Goal Orientations and Math Achievement in Primary Grades: A Follow- Up Study. Scandinavian Journal of Educational Research, 54(3), 295-312. doi: 10.1080/00313831003764545

Meece, J. L., Anderman, E. M., \& Anderman, L. H. (2006). Classroom goal structure, student motivation, and academic achievement. Annual Review of Psychology, 57, 487-503. doi: 10.1146/annurev.psych.56.091103.070258

Newman, R. S., \& Schwager, M. T. (1995). Students' help seeking during problem solving: Effects of grade, goal, and prior achievement. American Educational Research Journal, 32(2), 352-376. doi: $10.2307 / 1163435$

Nunes, T., Schliemann, A. D., \& Carraher, D. W. (1993). Street mathematics and school mathematics. New York, NY US: Cambridge University Press.

Pintrich, P. R. (2000). Multiple goals, multiple pathways: The role of goal orientation in learning and achievement. Journal of Educational Psychology, 92, 544.

Ridley, D. R., \& Novak, J. D. (1983). Sex-related differences in high school science and mathematics enrollments: Do they give males a critical headstart toward science- and math-related careers. Alberta Journal of Educational Research, 29, 308.

Roediger, H. L., III, \& Butler, A. C. (2011). The critical role of retrieval practice in long-term retention. Trends in cognitive sciences, 15(1), 20-27.

Roeser, R. W., Midgley, C., \& Urdan, T. C. (1996). Perceptions of the school psychological environment and early adolescents' psychological and behavioral functioning in school: The mediating role of goals and belonging. Journal of Educational Psychology, 88(3), 408-422.

Sarama, J., \& Clements, D. (2009). Teaching Math in the Primary Grades: The Learning Trajectories Approach. Young Children, 64(2), 63. 
Seegers, G., \& Boekaerts, M. (1996). Gender-related differences in selfreferenced cognitions in relation to mathematics. Journal of Research in Mathematics Education, 27(2), 215.

Siegler, R. S. (1988). Individual differences in strategy choices: Good students, not-so-good students, and perfectionists. Child Development, $59,833$.

Siegler, R. S. (1996). Emerging minds: The process of change in children's thinking. New York: Oxford University Press.

Siegler, R. S., \& Jenkins, E. (1989). How children discover strategies. Hillsdale: Lawrence Erlbaum.

Siegler, R. S., \& Shipley, C. (1995). Variation, selection and cognitive change. In T. Simon \& G. Halford (Eds.), Developing cognitive competence: New approaches to process modeling (pp. 31). Hillsdale, NJ: Erlbaum.

Steffe, L. P., Cobb, P., \& von Glaserfeld, E. (1988). Construction of arithmetical meanings and strategies. New York: Springer-Verlag.

Stipek, D., \& Mac Iver, D. (1989). Developmental change in children's assessment of intellectual competence. Child Development, 60, 521.

Svenson, O., \& Sjöberg, K. (1983). Evolution of cognitive processes for solving simple additions during the first three school years. Scandinavian journal of psychology, 24(2), 117. doi: 10.1111/j.14679450.1983.tb00483.x

Weinberger, N., \& Stein, K. (2007). The role of gender and gender composition on early competitive game playing. Paper presented at the Society for Research in Child Development. 
54 Carr et al. - Peers Influence Strategy Use

Martha Carr is Aderhold Distinguished Professor of Educational Psychology at the College of Education, University of Georgia.

Nicole Barned is a researcher at the Department of Educational Psychology at the University of Georgia.

Beryl Otumfuor is a researcher at the Department of Educational Psychology at the University of Georgia.

Contact Address: Martha Carr, Department of Educational Psychology, University of Georgia, Athens, GA 30602. Email: mmcarr@uga.edu 


\section{Appendixes}

Appendix A

\section{Individual Session Problems}

$3+6 \quad 9+4 \quad 28+6 \quad 8+13 \quad 8+9 \quad 12+6$

$12-9 \quad 5-3 \quad 9-4 \quad 33-6 \quad 17-5 \quad 10-6$

$11-?=6 \quad 5+?+6=13$

1. One friend has 15 stickers, he gives 9 of them to his friend. How many stickers does he have left?

2. Paul has 3 playing cards, Paul gives a card to Bill and a card to Evan. How many cards does Paul have left?

3. Ashley has eight candies. Ashley gives six of them to her friends. How much does she have for herself?

4. Donna has thirteen dolls. She wants six more of them. How many dolls will she have?

5. Shawn loves to read. He has eleven books now. Bob gives him four books. Pat gives him another four books. How many books does he have now?

6. Your teacher has five markers. She buys seven more markers. How many markers does she have now?

Group Session Problems (new problems)

$11+?=1515+?=225+?=12$ 